\title{
TITANIUM SHEET HOT FORMING IN THE AEROSPACE INDUSTRY
}

\author{
Guillaume SANA ${ }^{1}$ \\ ${ }^{1}$ ACB - 27 rue du Ranzai, 44319 Nantes, France
}

\begin{abstract}
$\underline{\text { Abstract }}$
Technologies dedicated to hot forming of titanium sheet are key processes for the manufacturing of structural and engine parts in the aerospace industry. The evolution of these processes in the past years is strategical taking into account the on-going increase of production rate of commercial aircrafts as single aisle and long-range civil aircrafts.
\end{abstract}

Starting from the use of single superplastic forming press, the state-of-the art has evolved to the use of automated forming cells from one side and to the development of the Hot Forming process on the other side. These evolutions are pushed by the aerospace market and its needs of a strong and efficient supply chain.

In order to assure production rate, cost saving and part quality to our customer, Aries Alliance offers tailor made solutions adapted to each customer need. From the delivery of fully-automated smart press cell to serial part production Aries Alliance is able to provide smart answer to the challenges brought by end-users. One of the roles of this niche industry is also to promote titanium applications challenged by the market facing strong competition from lightweight alloys like Al-Li or composite materials especially for aerostructure applications.

Keywords: titanium, hot forming, superplastic forming, presses, automated production cell, aerospace industry

\section{$\underline{\text { I. Introduction }}$}

Titanium alloys as Ti-6Al-4V or Ti-6242 are widely used in commercial and military aircrafts mainly for high temperature applications like in nacelles, pylons or engines or in corrosive environment. Even 
though they show excellent mechanical, physical and chemical properties, the main technical disadvantage of these alloys is their poor formability at room temperature. One solution to overpass this hurdle is to form these alloys at high temperature in the range 650 to $950^{\circ} \mathrm{C}$ depending on the part geometry. Considering parts based on sheet forming meaning thickness generally in between 0.6 and 6 $\mathrm{mm}$, two main processes are usually applied in the aerospace industry: Superplastic Forming (SPF) and Hot Forming (HF). Both process principles and corresponding presses will be introduced and typical applications will be presented to better understand what kind of advantages these equipment can bring in regards to the increase of production rate and part quality requirements.

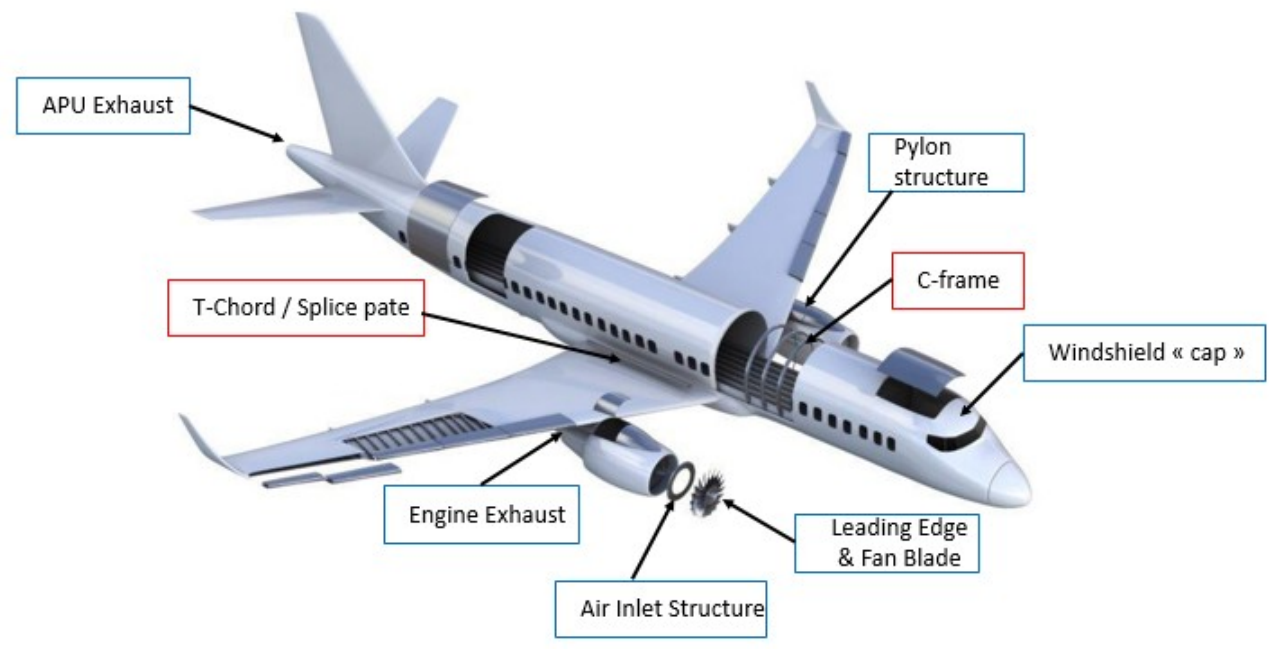

Figure 1: picture showing location of typical high temperature titanium parts in a commercial aircraft

\section{Process principles and presses}

\section{II.a. Sheet formability}

There are lot of parameters that could define the formability of a metallic alloy. Most of them are linked with the mechanical properties of the material and especially the yield strength. As the part must be 
considered as well as the material it is also important to take into account its geometry and shape. Considering the Ti-6Al-4V, the yield strength is decreased by a factor 3 between room temperature and $700^{\circ} \mathrm{C}$ and up to a factor 100 at $900^{\circ} \mathrm{C}$ [1]. In the same way if the formability can be characterized by the ability of the material to be bent taking into account one sheet of a defined thickness, the experiment shows that the bending ratio that represents the ratio between the bending radius and the sheet thickness decreases drastically at high temperature. As an example, at room temperature the minimum radius that can be obtained after bending process for a $1 \mathrm{~mm}$ thick titanium sheet will be around $4.5 \mathrm{~mm}$ and this minimum radius will decrease to around $1 \mathrm{~mm}$ at $800^{\circ} \mathrm{C}$ (figure 2). In fact, the more geometrical details the part contains, the hotter the temperature should be to be sure to get the requested geometry.

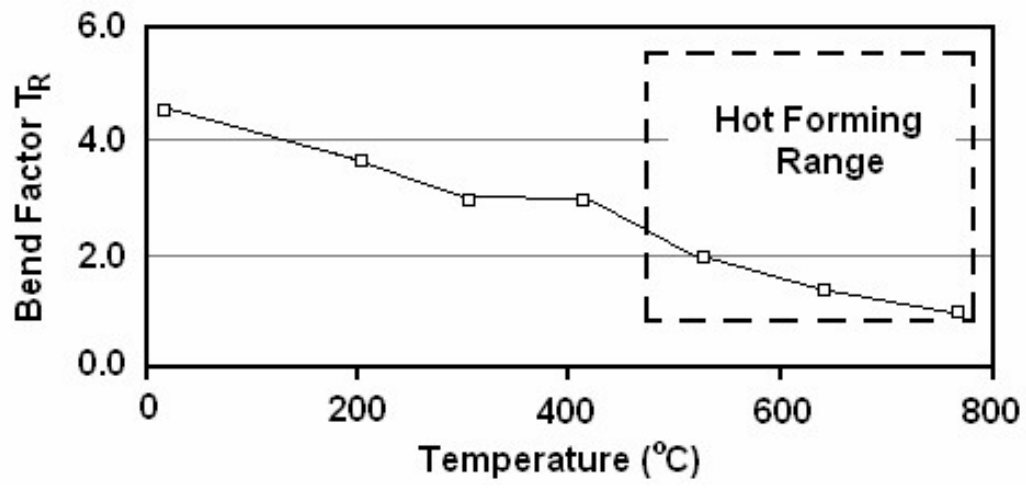

Figure 2: Titanium sheet formability vs. temperature [1]

Another parameter to consider is the spring back effect. At room temperature the spring back effect is very high especially on titanium alloys like Ti-6Al-4V or Ti-6242. When performing Hot Forming, the last step of the forming cycle consists of a holding phase under mechanical force at forming temperature in order to release internal stresses generated during forming cycle. This stress relief effect is efficient only after a defined holding time [3]. Hence when the part is unloaded from the press the part is almost free of residual stress ensuring good and repeatable geometry and avoiding geometrical distortion during post-processing operation like trimming or machining.

To summarize the use of heat to make the forming of titanium alloy easier brings following main advantages:

- Forming of details on part

- Accurate and repeatable shape of part 
- No or very weak residual stress inside part

The two main processes used to form titanium at high temperature in the aerospace industry are Superplastic Forming (SPF) and Hot Forming (HF).

\section{II.b. Superplastic Forming}

The SPF process has been developed in the 70's mainly for military applications. The process is based on the use of gas pressure applied on the titanium sheet at temperature generally above $880^{\circ} \mathrm{C}$ for Ti-6Al$4 \mathrm{~V}$. The titanium sheet is loaded in a die already heated at forming temperature, the die is closed by a cover. When the sheet is at forming temperature gas pressure, generally argon, is applied following a defined pressure cycle in order to inflate the part until complete contact between part and die surface. Very detailed description of the process has been reported in several scientific papers and especial by Hamilton and Partridge [3]. The die is located in a SPF press composed of two platens equipped with heaters. Main functions of the press are to compensate the gas pressure and keep the die closed during forming cycle and to heat up the die.

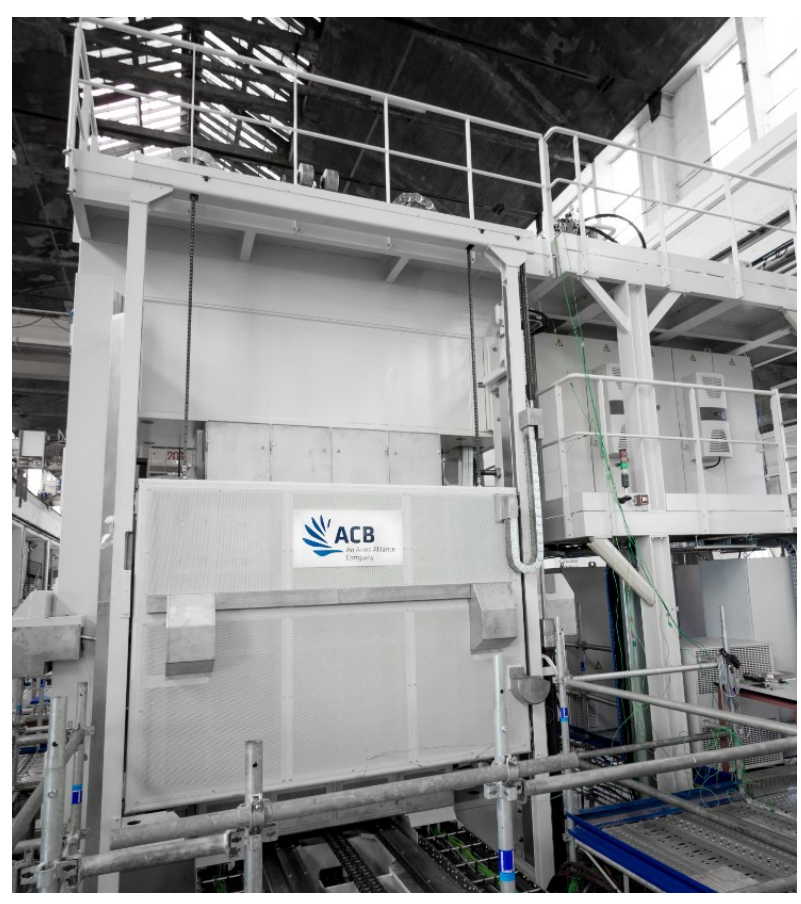

Figure 3: picture of SPF press 
Advantages of SPF process are the ability to form parts with very complex shape and to produce part without spring back and free of residual stress. A direct consequence of the SPF process, as the elongation is the main phenomena that occurs, is the heterogeneity of thicknesses on the final part. Nowadays there is no comparable or competing process that is able to bring advantages shown by SPF process. However this particular process is used only if no other forming technology can be applied or in case of combination with Diffusion Bonding. For example a well-known application of SPF/DB in the aerospace industry is the manufacturing of titanium hollow fan blades [4, 5].

\section{II.c. Hot Forming}

The Hot Forming process has been exploited in the aerospace industry in the 90's. The process is based on the mechanical action of a punch in a die in an isothermal environment. Hot Forming can sometimes be confused with hot stamping or even press hardening. Main differences are the forming parameters and the cycle itself. In hot stamping or press hardening, the blank is commonly heated outside of the press in an auxiliary furnace and then very quickly transferred to the press in a cold or warm die. The forming cycle itself last only few seconds considering a very fast punch motion generally around $100 \mathrm{~mm} \cdot \mathrm{s}^{-1}$. In hot stamping the blank is unloaded just after the die closing. For press hardening a quenching phase is performed in the die as it content a complex network of cooling channel to enable heat treatment just after forming. This process is particularly applied for boron steel and more recently on aluminum in the automotive industry [6]. In Hot Forming the system is considered isothermal, meaning that the press, die and blank are at the same temperature during the forming cycle. Moreover the punch speed often not exceed $10 \mathrm{~mm} \cdot \mathrm{s}^{-1}$ and corresponding strain rate inferior to $0.1 \mathrm{~s}^{-1}$. The last but not the least is the forming cycle constitution. In Hot Forming the cycle is completed by a holding phase where the die is maintained closed with a predefined force applied on the part. This holding phase is of first importance as it enables stress relief of internal stresses generated during the forming cycle and eliminates spring back effect [7]. It brings a real advantage to the Hot Forming process in the aerospace industry ensuring good part quality and repeatability.

In Hot Forming, the forming temperature is lower than SPF, on Ti-6Al-4V the typical forming temperature is around $680^{\circ} \mathrm{C}$. The die is positioned on the lower platen and the punch is fixed on the upper platen. The upper platen moves down to form the blank and calibrate it in the die shape. The speed, position and the force applied by the upper platen is ensured by an accurate hydraulic system. 


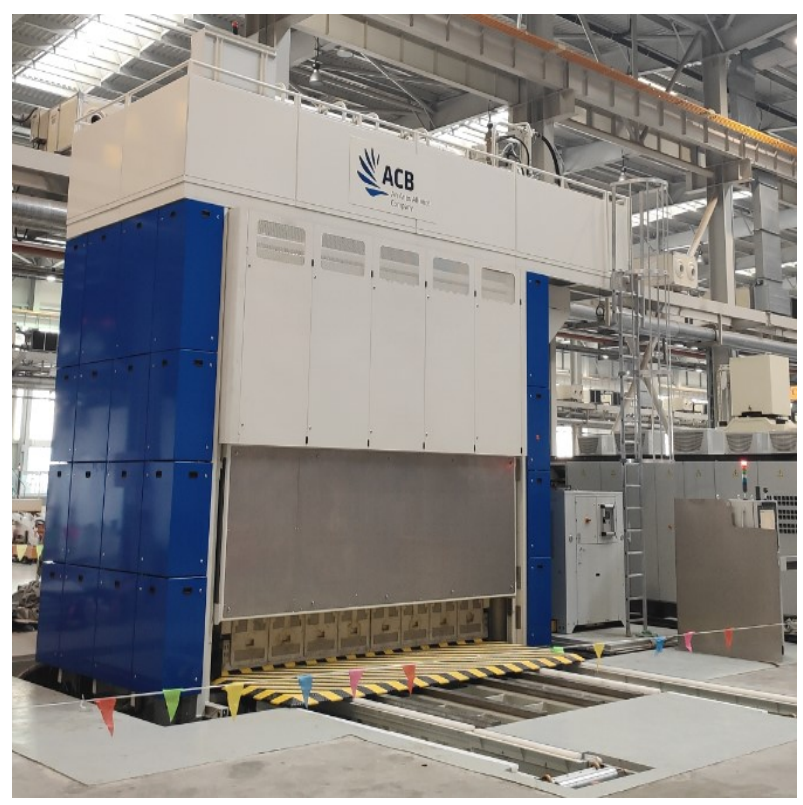

Figure 4: picture of HF press

In comparison with SPF process the cycle time is drastically reduced but the advantage regarding the absence of spring back and residual stress is kept. Moreover, most of final parts formed using Hot Forming show a very homogeneous thickness permitting an optimization of the initial blank thickness and thus direct cost savings on raw material. This is one of the reasons why this process has been widely developed in the past two decades. Nevertheless, HF process shows its limit for parts showing a high level of details or very deep drawing. In this last case, lot of studies have been led by several teams of the Aries Alliance group to overpass this type of hurdle. One solution has been the integration of a cushion function directly integrated in the hot environment of the press enabling the use of a blank holder effect very similar to system used on conventional cold stamping press. This function permitted to introduce a new process combining Hot Forming and Superplastic Forming [8, 9].

\section{II.d. Hybrid process}

The aim of this process is to combine benefits of both processes: thickness homogeneity, thin $\alpha$-case layer, short cycle time. Ti-6Al-4V has been considered for this project with blank thickness from 2 to 3 $\mathrm{mm}$. Microstructure of the material is an alpha-beta microstructure with equiaxed alpha grains with 
average size of 5 microns in a beta matrix. The heart of the process is to use Hot Forming as much as possible in the forming process and then to calibrate the part using gas pressure. The complete cycle must be performed at a unique temperature in the range $625-900^{\circ} \mathrm{C}$ to be cost effective. Material characterization have been made at several temperature and strain rate to define the impact of the strain rate changes in the same forming cycle on the material microstructure at a given temperature. One conclusion was that dynamic recrystallization occurs during Hot Forming with grains size generation at the grain boundaries with diameter less than 2 microns. Thus the material shows a superplastic behavior even at lower temperature than conventional SPF $[8,10]$.

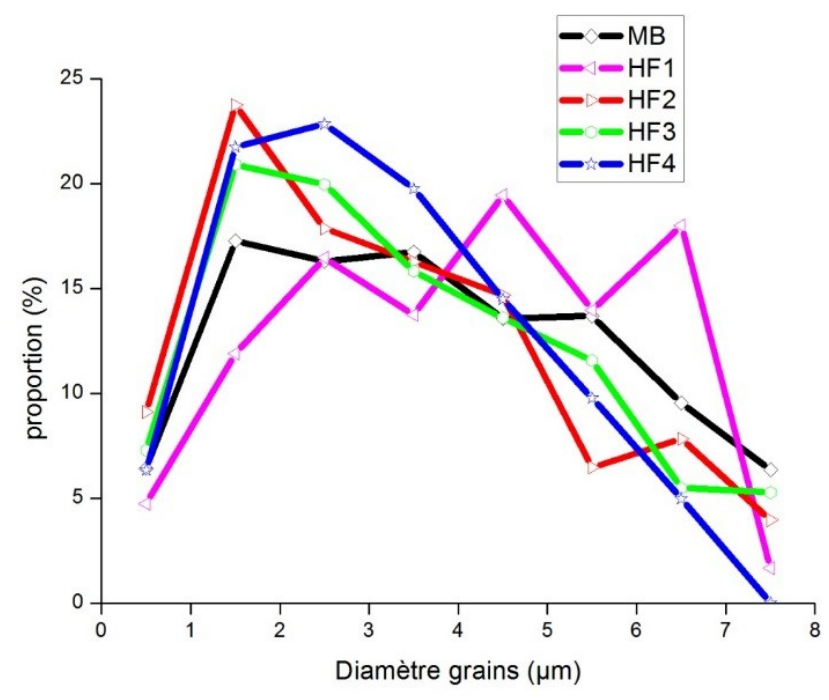

Figure 5: Evolution of grain size for different deformation after Hot Forming [10]

Next steps have been the constitution of material law to enable the use of finite element calculation to simulate the process and the manufacturing of several demonstrators with dimensions up to 2 meters in length. This project has conducted ACB to develop dual presses. As the hybrid, also called dual, machine concept combines both processes capability and can work either in HF mode or in SPF mode or a combination of both depending from the part to produce which it brings lot of flexibility to the user. 


\section{Case study: Hot Forming production cell}

The backlog on commercial aircraft market is increasing year after year. In the meantime, the monthly production rate is also increasing. If just considering AIRBUS Group, the production rate already reached up to around 60 aircrafts per month for single aisle and 10 aircrafts per month for long range category [11].

A direct consequence is the increase of titanium parts required by Tier 1, Tier 2 suppliers and aircrafts manufacturers. For a long time titanium alloys such as Ti-6Al-4V has been considered as an expensive and difficult to work alloy in comparison with aluminum or even today with composites like CFRP (Carbon Fiber Reinforced Polymer). However nowadays technologies developed in the past decades allow to produce hard metal parts in a simple way. Moreover specific equipment have been designed to achieve sufficient production rate to satisfy the supply chain challenges. For this reason, ACB has designed cutting-edge technologies, on one side for HF and SPF presses and on the other side for auxiliary equipment and automation.

For the production of titanium parts using HF process the cycle time is assessed to be around 30 minutes including loading and unloading of part in the press if done manually by the operator. In our case study the production is assured in 3 shifts for 240 days a year and 70 different tool references are used. Taking these hypotheses into consideration a standalone HF press will be able to produce approximately 3100 parts per year. It is possible to increase production capacity without multiplying the number of presses at unchanged forming parameter - using auxiliary equipment. If adding a preheating furnace for forming dies, a cooling cocoon and an automated hot die loader, the production rate can increase up to $125 \%$ with more than 7000 parts per year. This is mainly due to the optimization of production time as the press can stay hot most of the time and shows a better availability rate. 

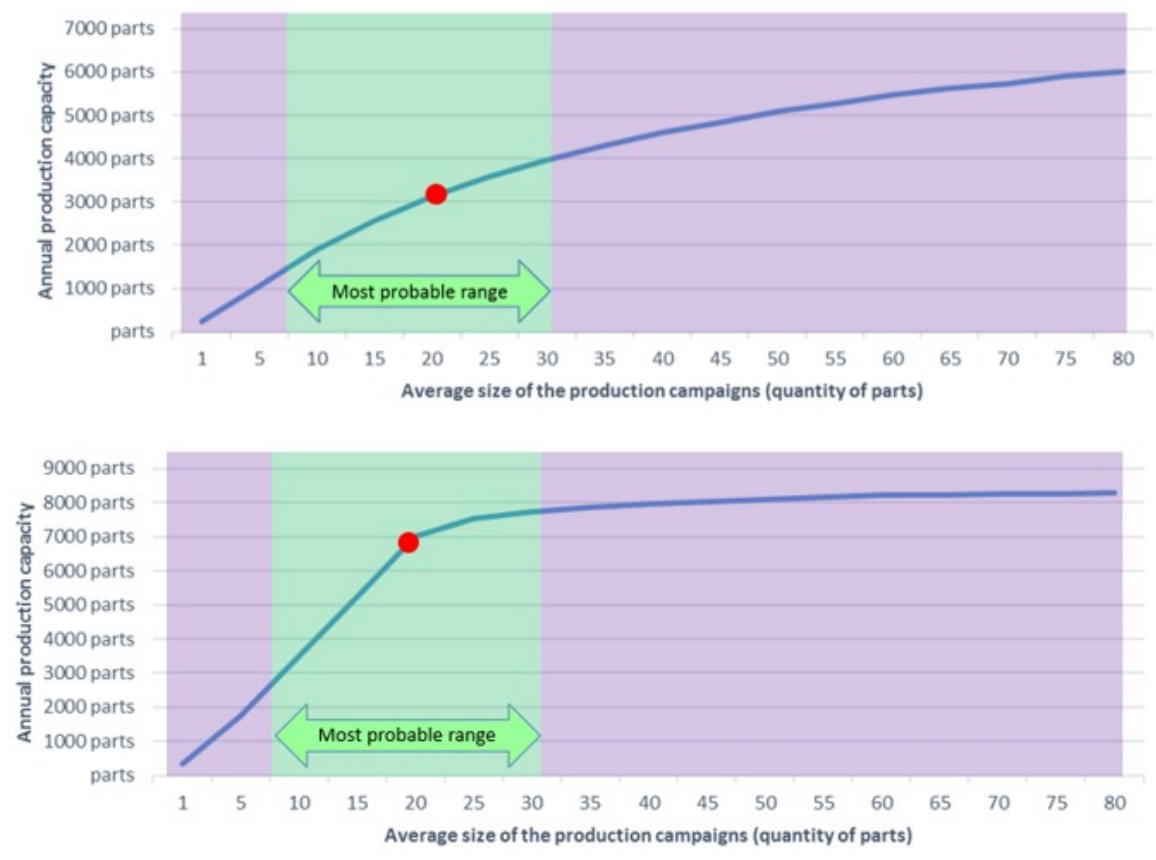

Figure 6: graph representing parts production capacity for standalone press (top) and automated HF cell (bottom)

In addition, the use of preheating furnace and cooling cocoon is a great advantage regarding die-life as the die can heat-up and cool-down gently to avoid any thermomechanical stresses and these operations are done in hidden time. From the operator point of view, the use of hot die loader and part handler is also a non-negligible improvement of safety when working close to hot environment. Finally, the use of all these auxiliary equipment enables the optimization of part quality and repeatability. This aspect is also emphasized as the production cell is controlled by a dedicated command system enabling to prevent maintenance or to identify defaults occurring during production. The press, or presses if several, and their auxiliary equipment are located in a close production cell where all transfer from one equipment to another is performed automatically without any action of the operator.

To complete this forming cell the group Aries Alliance has developed a dedicated technical solution for 2D and 3D laser trimming called Mantis machine. This machine integrates cutting-edge technologies enabling to perform laser trimming but mechanical drilling and finishing as well after forming. All these operations are combined on one machine and can be performed on two parts simultaneously depending on part dimensions. To conclude the automated HF production cell as described here above is typically 
the heart of so-called vertical integration. As regards of the Industry of the Future all these equipment can be connected together and communicate with users using a so-called MES system to collect most useful data for the production management.

All these products are mainly dedicated to titanium alloys as Ti-6Al-4V and Ti-6242 but are adapted to produce $\mathrm{Cp}-\mathrm{Ti}$ (T40, T60), $\beta$ titanium alloys ( $\beta 21 \mathrm{~S}$ ), or even superalloys (Inconel) or aluminum parts as well. In fact the versatility of these machines especially regarding the temperature range for forming press going up to $1000^{\circ} \mathrm{C}$ enables users to answer main demands of the aerospace market in term of elementary parts production.

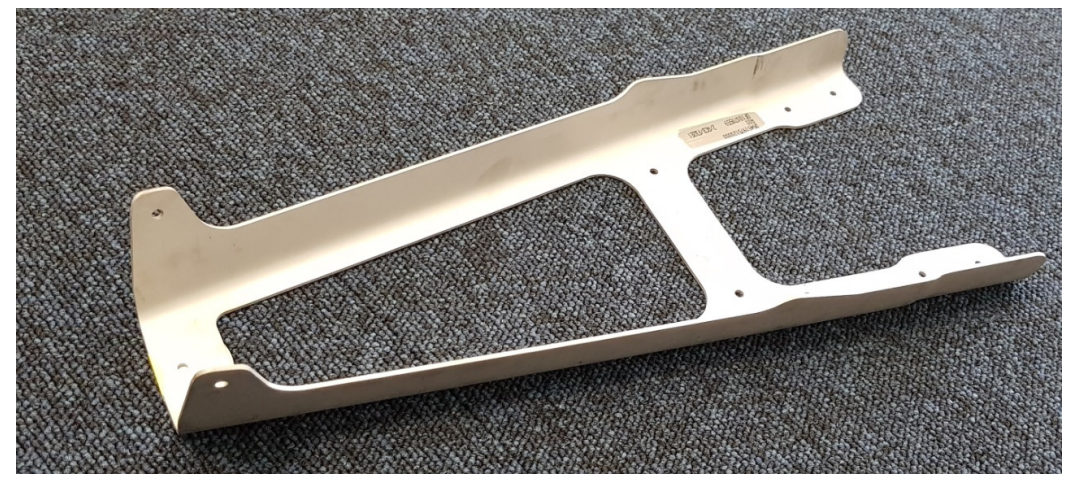

Figure 7: typical Ti-6Al-4V Hot Forming part after 3D-trimming and chemical etching

\section{CONCLUSIONS}

Hot Forming and Superplastic Forming processes have evolved, pushed mainly by the aerospace market and the huge increase of titanium parts in commercial aircrafts combined with the rise of aircraft production rate in past years. As the supply chain must be ready to answer Tier 1, 2 suppliers and aircraft manufacturer's demands it is not realistic to work with "handcrafted" solution where each operation is done manually. At this point one of the key words to answer this issue is automation. Lot of progress have been done in this field during the past decade and nowadays proven solutions are used to assure parts quality and repeatability and in the meantime presses reliability and safety.

All of this combined leads to an easiest way to produce and supply titanium parts mainly for aerospace applications but not only. Titanium shows extraordinary properties making it the perfect candidate for lot 
of applications and the role of actors of this niche market as Aries Alliance is to promote its use and support customers in this field.

\section{REFERENCES}

[1] Thesis - Material Characterization for Analyses of Titanium Sheet Metal Forming - Eva-Lys ODENBERGER - Luleå University of Technology - 2005

[2] Titanium Metal Corporation - Properties and processing of Timetal 6-4 - 1998

[3] AGARD Lecture Series N 154 - Superplasticity - 1987

[4] Superplastic Forming and Diffusion Bonding for Sandwich Structure of Ti-6Al-4V Alloy - W.HAN, K. ZHANG, G. WANG, X. ZHANG - Journal of material Sciences and technologies, Vol.21, No. 1 2005

[5] Establishing best practice in the design and manufacture of hollow titanium fan blade - G.A.

FITZPRATRICK and A.D. LOYD - RTO MP9 Intelligent Processing of High Performance Materials Brussels, Belgium - 1998

[6] A review of hot stamping - H. Karbasian, A.E. Tekkaya - Journal of Materials Processing Technology $210-2010$

[7] Hot forming process analysis of Ti-6AlV alloy: experiment, behavior modelling and finite element simulation - V. Velay et al. - Materials Science Forum, Trans Tech Publications Inc., 2016, 838-839, p. $183-189$

[8] Hot Forming and Superplastic Forming: Presses Evolution and New Applications in the Aerospace Industry - G. Sana, A. Petiot, A. Giraudet - Materials Science Forum - 2016

[9] Development of an advanced superplastic forming process utilizing a mechanical pre-forming operation - Y. Luo, S.G. Luckey, P. a. Friedman, Y. Peng - Int. J. Mach. Tools Manuf. 48 (2008) 15091518. 
[10] Characterization of the Influence of a Fast Preforming on Superplastic Forming - A. Giraudet, F.

Christien, F. Tancret - Proceedings of the 13th World Conference on Titanium, pp.1367-1372 - 2016

[11] Annual report GIFAS 2017-2018 (French Aerospace, Defense and Security Industry) 